\title{
Which Factors Affect Learner Achievement? Analysing the Role of Psychological, Surface Level, Environmental and Learner Effort Variables
}

\begin{abstract}
Ahmed Al-Azawei ${ }^{1,2, *} \&$ Karsten Lundqvist ${ }^{1}$
${ }^{1}$ School of Systems Engineering, University of Reading, Reading, UK

${ }^{2}$ College of Information Technology, University of Babylon, Babel, Iraq

*Corresponding author: School of Systems Engineering, University of Reading, Whiteknights, PO Box 217, Reading, Berkshire, RG6 6AH, United Kingdom. E-mail: a.al-azawei@pgr.reading.ac.uk
\end{abstract}

Received: April 13, 2015

Accepted: May 15, 2015 Published: May 29, 2015

doi:10.5296/ije.v7i2.7433

URL: http://dx.doi.org/10.5296/ije.v7i2.7433

\begin{abstract}
The meshing hypothesis of learning styles suggests that matching teaching and learning styles can promote learning experience. In this research, learning styles (psychological variable), gender diversity (surface level variable), learning modes (environmental variable), and learning time (learner effort variable) were integrated in a model in order to explore their pedagogical impacts on learner performance. The investigated learning environments adopted the traditional teaching approach of 'one-size-fits-all'. Variables of 59 undergraduate students were measured using the Index of Learning Styles (ILS), an academic record, and a log file of Moodle system. Based on the proposed model, the identified hypotheses were quantitatively analysed. Surface level, environmental, and learner effort variables showed to have a significant effect on learner performance. However, the meshing hypothesis could not be proven. This suggests that other variables are more likely to influence achievement than learning styles.
\end{abstract}

Keywords: Learning Styles, Gender Diversity, Learning Modes, Learner Effort, Learner Achievement 


\section{Introduction}

Many factors have been investigated to address issues that may face learners in different learning environments. These cover, for instance, background, demographic factors, prior knowledge, working memory capacity, information processing speed, goals, interests, and learning styles. According to literature, learning styles have widely been used to avoid a 'one-size-fits-all' teaching approach (Akbulut \& Cardak, 2012; Al-Azawei \& Badii, 2014; Dorça, Lima, Fernandes, \& Lopes, 2013; Felder \& Brent, 2005). The assumption of this trait is that teaching all learners in a one way can negatively influence learning experience due to the obvious differences among learners. As such, educational settings have to be catered to individual styles. Contrary, Riener \& Willingham (2010) argued that scientific evidence proved that learners are unequal in their abilities, talents, interests, and prior knowledge, but learning styles hypothesis has not been proven. Accordingly, the effectiveness of integrating learning styles in educational practice should precisely be explored. The investigation must treat learning styles as a possible one factor which may impact learning experience. Moreover, the failings of the 'one-size-fits-all' as applied in teaching delivery can be tackled if learning styles show to affect learning process.

Although learning styles assumption occupied a considerable attention, many issues still surround it. One of these is that an obvious definition is unavailable. Felder (1996) defined learning styles as "characteristic strengths and preferences in the ways they take in and process information". This, on the other side, overlaps the concept of cognitive styles (Al-Azawei \& Badii, 2014). Other debate exists with regard to this trait are the overlap among terminologies, stability, and validity of available measurements (Coffield, Moseley, Hall, \& Ecclestone, 2004; Zhang, 2013). Coffield et al. (2004) reviewed 71 learning style models to state that only thirteen models have shown a strong influence in the field of style due to their robust theoretical base, domination of use, and impacts on other models.

Examples of such commonly used models are: Dunn and Dunn model (Dunn \& Dunn, 1974), Kolb's model (Kolb, 1981), and Felder and Silverman model (Felder \& Silverman, 1988). In this research, the Felder and Silverman model was adopted. According to reported studies, this model was widely used, more specifically, in Technology Enhanced Learning (TEL) (Akbulut \& Cardak, 2012; Al-Azawei \& Badii, 2014; Graf, Viola, \& Leo, 2007). Additionally, it was proposed for engineering students where our sample was chosen.

Based on the meshing hypothesis of learning styles (Pashler \& McDaniel, 2008), this study was motivated. It incorporated learning styles as a deep level variable, gender diversity as a surface level variable, environmental variable, and learner effort variable in the proposed model. The psychological trait was used as the central factor. The aims of this integration were to link the role of learning styles with learning modes to in-depth explore their pedagogical implications. Then, to compare the impacts of all integrated factors on educational practice. 


\section{Learning Modes}

\subsection{Traditional learning mode}

Traditional learning represents the most dominant learning method that is applied in teaching delivery when learners and teachers are physically in a same place and time. Other synonyms to this category are classroom, physical classroom, and Face to Face (F2F) learning. The main features of F2F approach is the direct interaction between learners and teachers for clarifying unclear concepts, learners can easily collaborate with other peers to get better understanding, and verbal and social abilities of learners can be improved (Nussbaum et al., 2009). In contrast, it is usually impossible to adapt teaching approaches to cater for preferences of every student in large classes. As a consequence, learners are forced to learn by adapting to teachers styles. This could be a positive point because a teacher represents an expert in a particular subject. Contrary, they might struggle to adapt to a particular teaching approach. The restrictions of time, place and costs are other issues in this mode. This leads to developing other learning methods to overcome such drawbacks.

\subsection{Blended learning mode}

As with other new terminologies in the area of learning, 'blended learning' does not have an acceptable definition by all researchers. Simply, blended learning can be identified as the use of two or more learning modes provided that traditional learning is one of them. According to Garrison \& Kanuka (2004), blended learning means "the thoughtful integration of classroom face-to-face learning experiences with online learning experiences". Procter (2003) stated that an acceptable definition for blended learning can be provided by integrating the concepts of learning and teaching styles. Hence, it was defined as "the effective combination of different modes of delivery, models of teaching and styles of learning". However, theoretically and practically using a form of distance or e-learning with F2F learning can be called blended learning irrespective of other constraints.

Using this mode could represent the optimal way of learning delivery since it combines the advantages of different modes as well as overcoming the shortages of individual one. As such, most educational institutions around the world have used Learning Management Systems (LMSs) alongside traditional classes to enhance, for example, learning delivery, flexibility, availability, and manageability.

\section{Felder and Silverman Learning Styles Model (FSLSM)}

Even though the model 'neither comprehensive nor original' (Felder \& Silverman, 1988), it was dominant in recent years, specifically, in Adaptive Educational Hypermedia Systems (AEHSs) (Akbulut \& Cardak, 2012; Al-Azawei \& Badii, 2014). The model was originally included five dimensions. In 2002, Felder excluded the inductive/ deductive and modified the visual/ auditory dimensions. The former was omitted because the dominant teaching approach in engineering settings is deductive. The latter, on the other hand, was modified because his perspective is that auditory comprises only spoken words or other sounds, whereas written 
words cannot be included under this category. Felder mentioned that the viewpoint of psychologists is that human brain converts written words into their equivalent of spoken words. Thus, verbal can include spoken and written words, but not vice versa. The new version of the model includes the following dimensions:

- Processing (active/ reflective): the main features of active learners are doing something, working in groups and more likely to be experimentalists. Reflective learners prefer to think about content and work alone.

- Perception (sensing/ intuitive): the most distinguishing features of sensing learners are: preferring facts, following instructors' approach of problem solving, and patient with details. In contrast, intuitive learners prefer complicated and abstract content and use their own approach in problem solving.

- Input (visual/verbal): visual learners prefer pictorial learning materials such as images, animations, graphs, videos and charts. Verbal learners tend to prefer explanation by other peers or instructors and written texts.

- Understanding (sequential/ global): the most preferences of sequential learners are learning step by step and without considering the whole picture, whilst global learners make leaps to understand the general picture and connect different concepts together. In order to explicitly diagnose learning styles in accordance with this model, the Index of Learning Styles (ILS) was proposed (Felder \& Soloman, n.d.).

\subsection{The Index of Learning Styles (ILS)}

This questionnaire consists of 44 items, freely available, and self-assessment instrument (Felder \& Soloman, n.d.). Each dimension is deduced by asking eleven questions. Learners should choose either (a) or (b) for each question. The (a) options are to infer the first pole, for example, active, whereas the (b) options are to identify another one. The scales are between +11 and -11 and only odd numbers are used. For instance, if a learner chooses an (a) option, the value is incremented by +1 , whereas if a (b) option is chosen, the value is decremented by -1 . Applying such scales facilitates the description of learner styles in more details and allows for diagnosing mild, moderate and strong preferences. The scores 1 and 3 mean that a user has a balanced or mild tendency, 5 and 7 represent a moderate style and the highest scores of 9 and 11 indicate a very strong preference.

\subsection{Critique of the ILS}

The accuracy of identifying learning style dimensions underlies the reliability and validity of a psychometric instrument that was proposed to infer a model. Reliability means "a measure of how free the scale is from random error", whereas validity refers to "how accurately a scale measures what it is intended to measure" (Pallant, 2013).

Hawk \& Shah (2007) stated that there is no adequate evidence to support the reliability and validity of the ILS. On the other hand, Zywno (2003) concluded that the four dimensions met the acceptable level of internal consistency reliability and the construct validity was proven. Felder \& Spurlin (2005) showed that the ILS was validated in ten universities and four 
countries based on English engineering population. Litzinger, Lee, Wise, \& Felder (2007) measured the reliability and validity of the questionnaire by participation of 448 undergraduate and postgraduate students. They fill in the original version and a modified one. The results indicated that the original version generated acceptable levels of reliability. Further, factor analysis and the feedback of students supported its validity. This leads to the conclusion that changing the instrument even to enhance it seems 'ill-advised'. In summary, reported literature showed that the ILS has widely been accepted irrespective of some critiques (Akbulut \& Cardak, 2012; Al-Azawei \& Badii, 2014). Figure 1 depicts this model and the scoring (1-11) that identifies learning styles of each dimension (adapted from Felder \& Silverman (1988)).

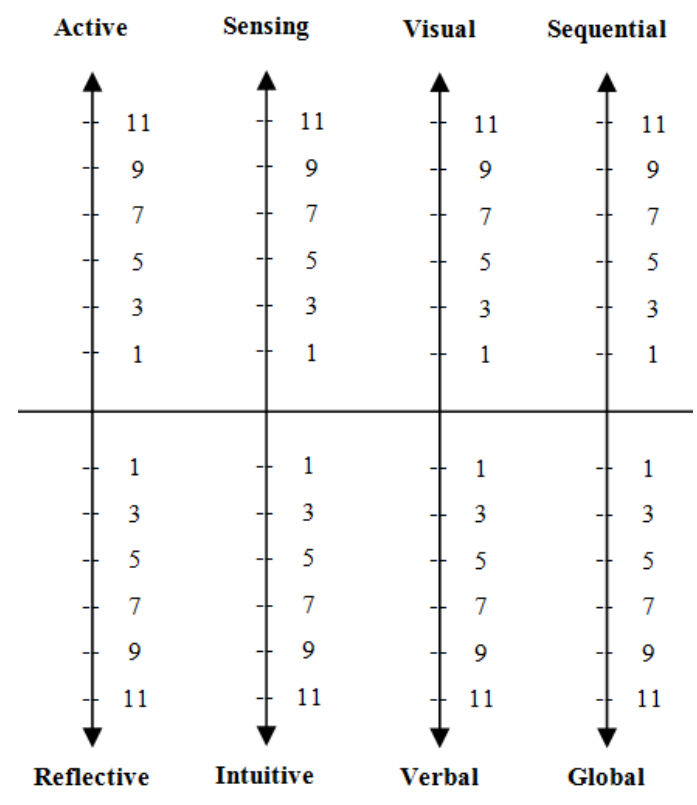

Figure 1. FSLSM and the Scores of ILS

\section{Theoretical Framework}

Studies have not produced conclusive evidence either for, or against, the possible impacts of learning styles on achievement. This indicates that further investigations are required to contribute providing evidence to inform our current state of knowledge. All learning style models were proposed to be used in the traditional learning. Psychologists suggest that instructors have firstly to identify learning styles of students. Then, teaching styles should be accommodated in accordance with learner preferences (Felder \& Brent, 2005; Felder \& Silverman, 1988). Empirical research focuses on distinguishing to which extent that learning styles affect learning outcome (Akbulut \& Cardak, 2012). This is due to the absence of adequate evidence to support the pedagogical implications of learning styles (Mayer, 2011; Pashler \& McDaniel, 2008). Hence, we linked learning styles with learning modes to explore the impacts of this trait on educational practice. Both investigated environments used a direct teaching approach. It means "a systematic way of planning, communicating, and delivering in the classroom" (Cagiltay, Yildirim, \& Aksu, 2006). This approach suggests that all learners can learn in the same speed and way. Accordingly, learning styles was incorporated to understand 
the differences of learner performance in such learning modes. Furthermore, to infer the complex correlation of other factors, surface level and learner effort factors were also integrated in the model.

In spite of the history of learning styles research, the pedagogical impacts of this trait have to thoroughly be searched (Mayer, 2011). According to the best of authors' knowledge, studies have not taken into account if the implications of learning styles link with a learning mode. Thus, this study contributes to reveal such relationship as well as comparing the pedagogical influences of several variables. Generally, the study concludes that learning styles did not seem to influence learning outcome whether in traditional or blended learning modes. Moreover, surface level, environmental, and learner effort variables showed to affect learner achievement. The effect of these variables was explained in accordance with subject matter, the social constructivist learning theory, and student engagement respectively.

\section{Learning Styles and Learner Performance}

A rigorous procedure has to be followed to examine the correlation between learning styles and learner performance. Participants should be divided into matching, mismatching and control groups. Then, all groups should perform a summative assessment to compare the results. This procedure was not followed in this research because it aims to explore the role of learning styles in non-adaptive learning environments where preferences of some learners were mismatched. Brown, Brailsford, Fisher, \& Moore (2009) stated that most empirical studies did not consider the statistical significance of learning styles and there was a bias of choosing a sample. Such failings might reveal the reason that underlies producing inconsistent results.

In the study that performed by Chamillard \& Sward (2005), learning styles of 80 students were inferred using the ILS, LSI of Kolb and the Keirsey Temperament Sorter. A persistent synergy between learner achievement and learning styles was found. Zapalska \& Brozik (2006) used VARK model to identify learning styles. Although the research concluded that performance can be improved if teaching and learning styles are matched, it did not show any statistical results and the sample size was quite small (25 undergraduate students).

In contrast, the influence of learning styles, learning patterns, and demographic factors (age, gender, online learning experience, ethnic groups, and job status) on learner performance were tested by Lu, Yu, \& Liu (2003). The statistical results showed that learning styles did not affect learner performance. Similarly, Brown (2007) examined the influence of two dimensions of FSLSM (visual/ verbal and sequential/global) in two case studies. In the first one, the input dimension (visual/ verbal) of 109 students was deduced, whereas the understanding dimension (sequential/ global) of 82 students was identified in the second case study. Students were randomly partitioned into match, mismatch and neutral groups. The study was carefully designed and data were quantitatively analysed. The overall results did not show any significant relationship between learning style dimensions and learning outcome. This finding was supported by Campbell \& Johnstone (2010). Kolb's learning style model was adopted to deduce learners' styles. A total of 74 undergraduate students in a programming course were 
included in the experiment. ANOVA test was used to examine the identified hypotheses: "H0: Students of each KLSI group achieve the same results, H1: Students of each KLSI group achieve different results". As a result, the null hypothesis was not rejected.

\section{Research Methodology}

\subsection{Study sample}

A total of 59 students represented the subject of the study. This sample size is sufficient in order to conduct a quantitative analysis. According to Pallant (2013), 30 participants can be considered as an acceptable sample size in the quantitative method. Their age ranged from 18 to 26 where the majority of them were from 18 to 20 (74.57\%). Furthermore, females participated more than males (male $=25$ and female $=34$ ).

\subsection{Contexts}

The first course was Fundamentals of Programming Language I (FPL I). This course was taught using a Face to Face learning. Before the end of the semester, students were requested to use Moodle. However, because of the time constraint and low experience of students in e-learning systems, they could not use it properly. This leads to solely relying on the traditional classes. In the second semester, Moodle was fully applied to support the traditional learning. Hence, students have studied the Fundamentals of Programming Language II (FPL II) in a blended learning environment.

The courses were similar except that the first one was shorter because of a registration issue for the first semester and first year students which needs some time. The FPL II was delivered over a 14 week term. Both courses comprised two hours of lectures and two hours of laboratory work per week. All learning materials of the second course were uploaded as pdf or ppt files to the Moodle learning management system to improve discovery and retrieval. In order to enhance students' social interaction, they were encouraged to use communication tools of Moodle such as forum and wiki.

\subsection{Data collection}

\subsubsection{Research instrument}

All students consented to participate in the study. They were requested to fill in the questionnaire in the classroom and using announcement page of Moodle. The instrument consisted of two parts. While the first one identified demographic features of participants, the second part comprised the ILS. All questions were translated into Arabic language because undergraduate students in Iraq have a modest English ability. This can facilitate understanding of questions and saving participants time.

\subsubsection{Academic record}

The average of two written exams and one laboratory test as well as the weekly activities of learners in lectures were gathered to represent their performance in the first course. Same approach was used to assess student achievement in the second course except that two online 
tests were used instead of written exams.

\subsubsection{Log file}

Lu et al. [22] assumed that the total number of hits can be used as an indicator about the time that students spent to learn a subject. Based on this assumption, the number of hits on the course site as recorded in the log file of Moodle was used to account the time that students spent to learn the educational materials. The frequency of visiting the course site was divided into four categories: infrequent (0-50), less frequent (51-100), frequent (101-200) and very frequent (201-400).

\subsection{Research model and hypotheses}

The dependent variable is learner performance. It means the extent to which a learner meets his/ her goals and ambitions. The proposed model suggests that, psychological, surface level, environmental, and learner effort variables affect learning outcome (Figure 2). Six hypotheses were developed according to the model dimensions.

- Psychological variable: this represents the identified learning styles. It was dealt as the central variable in this analysis. Thus, we hypothesised that:

H1a: There is a positive effect of learning styles based on the ILS on learner performance in a traditional learning environment.

H1b: There is a positive effect of learning styles based on the ILS on learner performance in a blended learning environment.

- Surface level variable: Vanderheyden \& De Baets (2015) consider gender and age group as surface level variables that might affect learner satisfaction and performance. Based on their consideration, only gender was incorporated in our model. Other surface level variables such as ethnicity and age group were not taken into account because the sample was homogeneous that shared very similar characteristics.

H2a: There is a positive effect of gender diversity on learner performance in a traditional learning environment.

$\mathrm{H} 2 \mathrm{~b}$ : There is a positive effect of gender diversity on learner performance in a blended learning environment.

- Environmental variable: this represents learning modes. It was assumed that a learning environment affects student performance. As such, their achievement may change or improve according to this factor.

H3: There is a positive effect of learning modes on learner performance.

- Learner effort variable: learning time may indicate the effort that students spend during the course. It is difficult to know the time that students spent to study, more specifically, in the traditional learning. In online learning, the interaction with a system can give hints about the approximate time that they spent. Accordingly, the relationship between the total number of hits on the course site and learner performance was investigated. 


\section{Macrothink}

International Journal of Education

ISSN 1948-5476

2015, Vol. 7, No. 2

H4: There is a positive effect of learning time on learner performance in a blended learning mode.

\subsection{Data analysis}

The software SPSS (Statistical Package for the Social Sciences) version 22 for windows 7 was used. The analysis techniques included the computing of mean (M), frequency, standard deviation (SD), and Pearson coefficient correlation as descriptive statistics and t-test, ANOVA, and MANOVA as inferential tests.

Learning style scores, gender diversity, learning modes, and the total number of hits represent the independent variables, whereas student performance of in the academic year represent the dependent variable. The P-Value of (0.05) was adopted to examine the statistical significance among the identified factors.

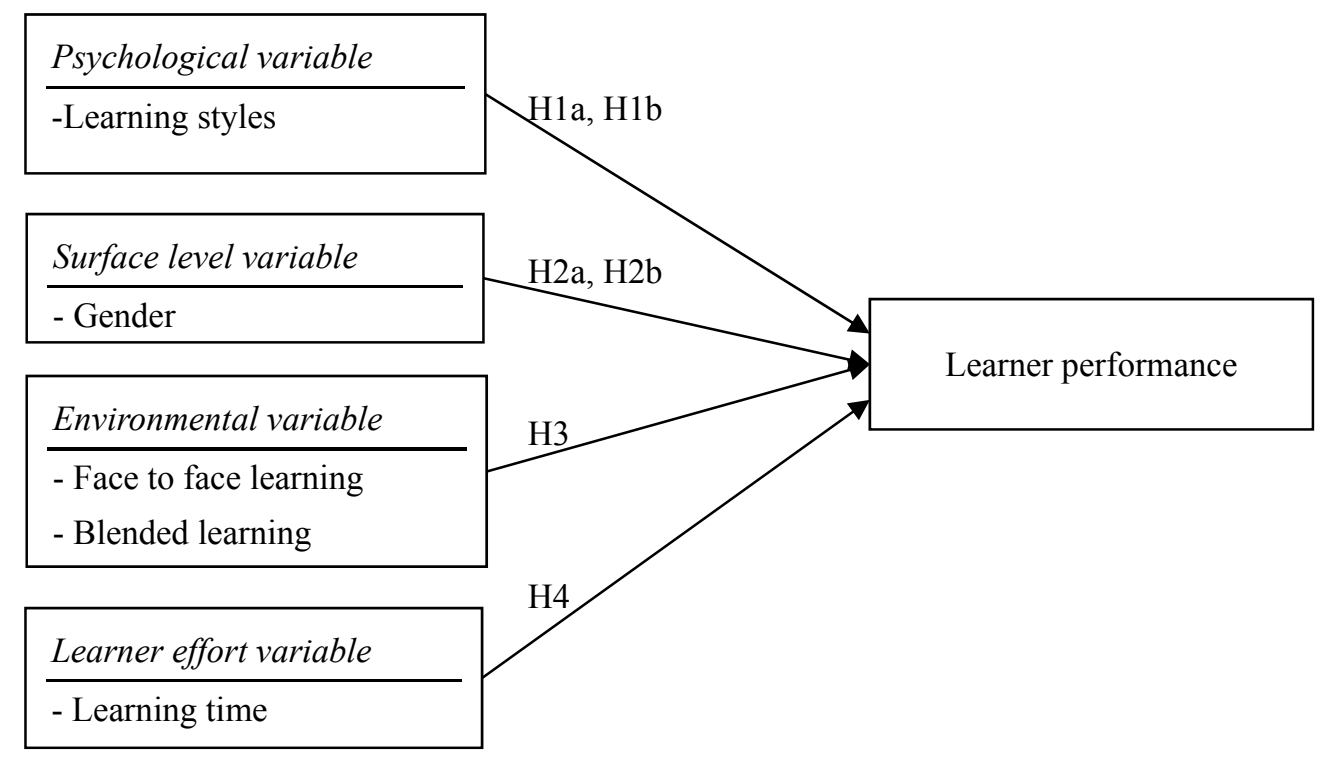

Figure 2. The proposed model

\section{Results}

The study aimed to thoroughly reveal the implications of different variables pertaining to student achievement. The distribution of the ILS scores indicated that the dominant styles of participants were active $(\mathrm{N}=38, \mathrm{M}=3.83, \mathrm{SD}=2.4)$, sensing $(\mathrm{N}=40, \mathrm{M}=4.75, \mathrm{SD}=2.83)$, visual $(\mathrm{N}=42, \mathrm{M}=5.1, \mathrm{SD}=2.89)$, and sequential $(\mathrm{N}=41, \mathrm{M}=3.93, \mathrm{SD}=3.1)$. This result is in agreement with the assumption of psychologists that engineering students are more likely to be active, sensing, visual, and sequential (Felder \& Silverman, 1988; Felder \& Spurlin, 2005). The normal distribution test of mean scores was conducted in both learning modes. As depicted in box plots (Figures 3 and 4 ) that the mean scores were approximately normally distributed for gender in both learning modes.

Pearson's coefficient correlation was applied to measure the correlation between gender and learner performance. In the traditional mode, a negative moderate correlation coefficient was found between mean scores and gender $(r=-0.418, P=0.001)$. This result to some extent is 
similar to the correlation coefficient in the second course $(r=-0.372, P=0.004)$. With regard to the relationship between average of scores and the total number of hits, a positive moderate correlation coefficient was revealed $(r=0.386, P=0.003)$. The correlation between gender diversity (surface level variable) and learning styles (deep level variable) was also measured using MANOVA test. Males significantly tended to adopt visual preferences than females as depicted in Table 1.

Table 1. The relationship between gender and learning style $($ Male $=25$, Female $=34)$

\begin{tabular}{|c|c|c|c|c|}
\hline & Gender & $\mathbf{M}$ & SD & MANOVA \\
\hline \multirow{2}{*}{ Active/ Reflective } & Male & 3.58 & 2.24 & $F=1.3, P=0.52$ \\
\hline & Female & 2.94 & 2.02 & \\
\hline \multirow{2}{*}{ Sensing/ Intuitive } & Male & 3.58 & 2.16 & $F=2.16, P=0.14$ \\
\hline & Female & 4.66 & 3.08 & \\
\hline \multirow{2}{*}{ Visual/ Verbal } & Male & 4.92 & 2.53 & $F=5.41, P=0.024$ \\
\hline & Female & 3.51 & 2.07 & \\
\hline \multirow{2}{*}{ Sequential/ Global } & Male & 2.54 & 2.04 & $F=0.68, P=0.41$ \\
\hline & Female & 3.00 & 2.11 & \\
\hline
\end{tabular}

Table 2 summurises the research findings. ANOVA test was used to examine the correlation between the psychological variable and performance (H1a and H1b). Moreover, independent-samples t-test was performed to compare performance according to gender differences $(\mathrm{H} 2 \mathrm{a}$ and $\mathrm{H} 2 \mathrm{~b})$. Paired-samples t-test was applied to explore the statistical significance of the environmental variable (H3). We also conducted ANOVA test to reveal the role of learner effort variable (H4).

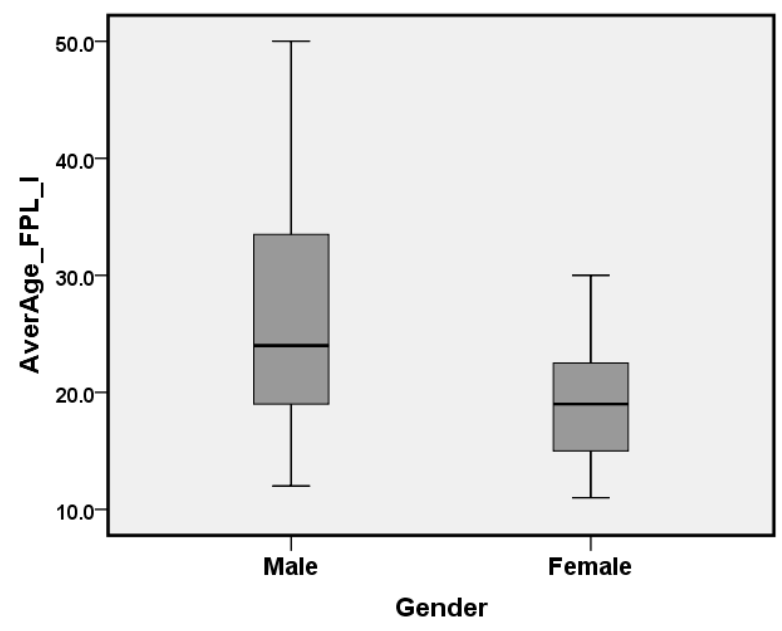

Figure 3. Gender and scores distribution in traditional learning mode

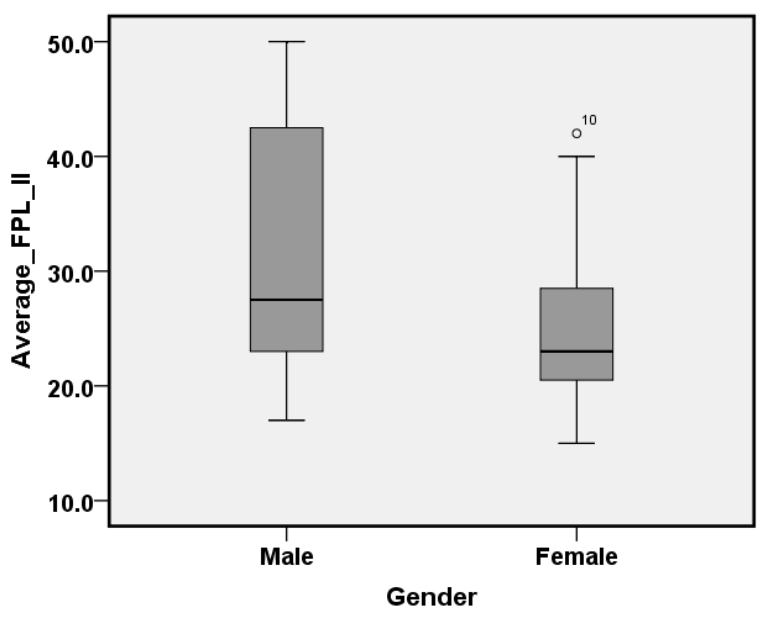

Figure 4. Gender and scores distribution in blended learning mode 
Table 2. The findings of the identified hypotheses

\begin{tabular}{|c|c|c|}
\hline Hypotheses & Statistics & Finding \\
\hline $\begin{array}{l}\text { H1a: Learning styles in the } \\
\text { traditional } \\
\text { environment. }\end{array}$ & $\begin{array}{l}F_{\text {Processing }}=3.117, P=0.083 ; F_{\text {Perception }}=2.210 \\
P=0.143 ; F_{\text {Input }}=0.002, P=0.964 ; \\
F_{\text {Understanding }}=0.015, P=0.903\end{array}$ & Rejected \\
\hline $\begin{array}{l}\text { H1b: Learning styles in the } \\
\text { blended } \\
\text { environment. }\end{array}$ & $\begin{array}{l}F_{\text {Processing }}=8.144, P=0.006 ; F_{\text {Perception }}=0.422, \\
P=0.519 ; \quad F_{\text {Input }}=1.227, P=0.273 ; \\
F_{\text {Understanding }}=1.54, P=0.22\end{array}$ & Rejected \\
\hline $\begin{array}{l}\text { H2a: Gender diversity in the } \\
\text { traditional learning } \\
\text { environment. }\end{array}$ & $\begin{array}{l}\text { Male }(25) \quad M=26.33, S D=10.2 \\
\text { Female }(34) M=19.4, S D=4.912 \\
T(57)=3.474, P=0.001\end{array}$ & Retained \\
\hline $\begin{array}{l}\text { H2b: Gender diversity in the } \\
\text { blended learning } \\
\text { environment. }\end{array}$ & $\begin{array}{l}\text { Male (25): } M=31.583, S D=11.1 \\
\text { Female (34): } M=24.657, S D=6.44 \\
T(57)=3.025, P=0.004\end{array}$ & Retained \\
\hline $\begin{array}{l}\text { H3: Learning modes and } \\
\text { learner performance. }\end{array}$ & $\begin{array}{l}\text { Traditional: } M=22.22, S D=8.217 \text {, Blended: } \\
M=27.475, S D=9.227 \text {, Paired-samples T-Test: } \\
T(58)=5.39, P<0.001\end{array}$ & Retained \\
\hline $\begin{array}{l}\text { H4: Learning time and learner } \\
\text { performance. }\end{array}$ & $\begin{array}{l}P(\text { Welch Test })=0.008, \\
P(\text { Brown-Forsythe Test })=0.04\end{array}$ & Retained \\
\hline
\end{tabular}

Although the results of ANOVA test of $\mathrm{H} 1 \mathrm{a}$ and $\mathrm{H} 1 \mathrm{~b}$ did not show a significant difference among learner performance and learning style groups, further analysis was conducted using t-test to reveal the differences of mean scores of each pole in the FSLSM. Overall results showed that reflective and intuitive learners did better than active and sensing students in both environments (Table 3). However, the differences were not significant except of processing dimension in the blended mode.

Table 3. The differences in the mean scores according to learning styles dimensions

\begin{tabular}{ll}
\hline \multicolumn{1}{c}{ Traditional Learning Mode } & \multicolumn{1}{c}{ Blended Learning Mode } \\
\hline$M_{\text {Active }}=21.3, S D_{\text {Active }}=7.9, M_{\text {Reflective }}=23.8$, & $M_{\text {Active }}=25.3, S D_{\text {Active }}=7.8, M_{\text {Reflective }}=31.2$, \\
$S D_{\text {Reflective }}=8.5, \mathrm{~T}(57)=3.025, \mathrm{P}=0.25$. & $S D_{\text {Reflective }}=10.5, \mathrm{~T}(57)=2.42, \mathrm{P}=0.019$. \\
$M_{\text {Sensing }}=20.9, S D_{\text {Sensing }}=7.49$, MIntuitive $=25$, & $M_{\text {Sensing }}=26.6, S D_{\text {Sensing }}=8.76, M_{\text {Intuitive }}=29.21$, \\
$S D_{\text {Intuitive }}=9.15, \mathrm{~T}(57)=1.82, \mathrm{P}=0.073$. & $S D_{\text {Intuitive }}=10.15, \mathrm{~T}(57)=0.99, \mathrm{P}=0.32$. \\
$M_{\text {Visual }}=22.1, \quad S D_{\text {Visual }}=7.3, M_{\text {Verbal }}=22.3$, & $M_{\text {Visual }}=26.7, \quad \mathrm{SD}$ Visual $=9.3, \quad \mathrm{M}_{\text {Verbal }}=29.3$, \\
$S D_{\text {Verbal }}=10.3, \mathrm{~T}(57)=0.78, \mathrm{P}=0.93$. & $S D_{\text {Verbal }}=8.9, \mathrm{~T}(57)=0.99, \mathrm{P}=0.32$. \\
$M_{\text {Sequential }}=\quad 22.2, \quad S D_{\text {Sequential }}=\quad 8.5$, & $M_{\text {Sequential }}=26.5, S D_{\text {Sequential }}=8.6, M_{\text {Global }}=29.6$, \\
$M_{\text {Global }}=22.2, \quad S D_{\text {Global }}=7.6, \mathrm{~T} \quad(57)=0.001$, & $S D_{\text {Global }}=10.4, \mathrm{~T}(57)=1.18, \mathrm{P}=0.24$. \\
$\mathrm{P}=0.99$. & \\
\hline
\end{tabular}




\section{Discussion}

\subsection{The psychological variable}

As previously discussed that convincing evidence either to confirm or to reject the possible implications of learning styles was not produced. In this investigation, learning styles did not seem to affect learner achievement in the traditional mode (H1a). In the blended environment, a consistent result was obtained, except of the processing dimension $(\mathrm{H} 1 \mathrm{~b})$. A reflective learner who uses an analytical strategy achieved significantly higher than an active one $(P=0.006)$. In the traditional learning, reflective learners also did better than active learners, but the difference was not significant $(P=0.083)$. Generally, literature showed that reflective learners performed better than active in programming courses (Allert, 2003). This might be accounted to the nature of such courses that requires deep reflection on learning content. This finding is in agreement with the assumption of this dimension as explained by Felder \& Silverman (1988). To precisely know how large the effect in this result is, the eta squared was calculated. It indicates a moderate effect of 0.09 as recommended by Pallant (2013). The finding may assume that learners can adjust their learning styles according to teaching approaches to contribute the studies that pointed out student performance is an independent from their styles (Brown, 2007; Campbell \& Johnstone, 2010).

\subsection{The surface level variable}

Studies on gender diversity and learner performance in programming courses produced inconsistent results (Lau \& Yuen, 2009). In the work that conducted by Pioro (2004), women did better than men in a programming course where their achievement was significantly higher in multiple-choices and programming problems measurements. Contrary, Lau \& Yuen (2009) showed that there was no significant gender diversity in programming performance. Furthermore, the effect of gender on the preferred learning approach was also examined to indicate that men are more likely to use a non-linear approach than women (Cagiltay et al., 2006).

In this study, gender diversity indicated a strong influence on learner performance. Men did better than women in the traditional and blended learning modes. Although, this is in agreement with the conclusion of Pioro (2004) that gender differences affect learner performance, it contrasts his finding to show that men achieved higher scores. The cross-cultural differences should be taken into account to explain such inconsistent results. With regard to the relationship between gender and learning styles, the significant difference was only found in the input dimension. Females tended to prefer verbal presentation than visual one $(\mathrm{P}=0.024)$. Boyle, Neumann, Furedy, \& Westbury (2010) stated that the achievement of women was significantly better than men in verbal tasks. This means that they prefer this type of presentation as revealed in this research. However, we did not find any differences in their performance according to visual/ verbal preferences.

The study suggests that gender has to be considered to accommodate programming courses in accordance with individual differences. However, the subject matter should not be neglected because this variable might affect learner performance in some courses, whereas it may not 
work in others. In order to help our academic understanding regarding the impact of gender diversity, we recommend examining this variable in different courses and cultures.

\subsection{The environmental variable}

As presented in Table 2, the paired-samples t-test showed that student achievement was influenced by learning modes (H3). They achieved significantly higher scores in the blended learning (Mean difference in the two scores was 5.25). Although such finding unlikely to occur by chance, the magnitude of the use of blended learning effect was calculated. The eta squared is equal 0.33. Pallant (2013) recommended that eta squared equal or greater than 0.14 represents a large effect. Thus, we concluded that there was a large influence of using blended learning on learner performance. Solimeno, Mebane, Tomai, \& Francescato (2008) examined the differences of learning modes on achievement in an online and face to face learning to state that there is no significant difference in overall learner performance. However, this study indicates that blended learning integrates the advantages of traditional and wed-based learning. This confirms studies that pointed out the positive implications of blended learning on learner performance and satisfaction (López-Pérez, Pérez-López, \& Rodríguez-Ariza, 2011).

The social constructivist learning theory highlights the significance of social interaction to construct knowledge. Using Moodle system as an assistant learning tool enhanced the interaction of 'learner-learner' and 'learner-instructor' because communication tools such as wiki and forum were activated in the course and students were encouraged to use them. Discussions and posts in the course site were readable by all participants. This obviously helped to clarify unclear concepts and/ or provide further explanations. Thus, students benefited from the physical classroom and out of the class interactions.

\subsection{The learner effort variable}

Pashler \& McDaniel (2008) identified many factors which leaded to the widespread use and popularity of learning styles. From one perspective, learners think that they can learn effectively when instructional courses are designed according to their styles. Similarly, when students cannot succeed in some courses, they tend to make the responsibility on an educational system rather than on themselves or the effort that they spent. This research showed that learning effort positively influences learner performance (H4). High frequent learners achieved better grades than students who used the system rarely. This supports the finding of $\mathrm{H} 3$ that the use of blended learning can improve learning outcome.

Unsurprisingly, students have to rely on their personal effort to meet their objectives and ambitions rather than blaming educational systems or their luck. In addition, the study encourages instructors to use effective learning technologies alongside the traditional method to engage their students and to enhance their learning ability.

\section{Implications and Limitations}

The added value of our study compared with literature is twofold. Firstly, the meshing hypothesis of learning styles was not supported in both learning modes. This contrasts the 
assumption of psychologists that ignoring learner styles leads to low achievement (Felder \& Brent, 2005; Litzinger et al., 2007). Although the styles and preferences of some learners were undoubtedly mismatched because the investigated environments adopted the direct teaching approach, this analysis suggests that learners can perform equally well in the traditional and blended learning irrespective of their styles. As such, it seems that educational institutions have to give attention to other variables in order to improve learning quality. Secondly, the study reveals the significant effect of gender diversity, environmental, and learner effort variables on learner performance to suggest that considering these variables are more beneficial than incorporating learning styles. Although using learning management systems alongside the traditional learning approach is still a new trend in some Arabic countries, our study encourages educational institutions to adopt such learning technologies to overcome the drawbacks of the traditional approach and to engage students.

Some limitations in the study have to be pointed out. A first restriction is that the sample was homogeneous. Collecting data from a heterogeneous population, several classes, and universities is more reliable to interpret findings out of contextual variables. Another possible limitation is that the total number of hits on the course site and learning time are unnecessarily correlated because inefficient browsers may need more time exploring learning content. On the other hand, this is the optimal way that we had to measure this variable. Finally, the collaborative approach to infer learning styles is an intrusive process. In a case of unwillingness of participants to be involved in a study, they may arbitrarily answer the questions. This represents the main reason that why we adopted the voluntary approach.

\section{Conclusion}

Learning styles was dealt as the central variable to empirically provide evidence about the feasibility of incorporating them in educational practice. Gender diversity, learning modes, and learning time were also integrated in the model. We concentrate on the role of learning styles in different learning environments. The study suggests that learning styles did not correlate with learner achievement neither in traditional nor in blended learning modes. The comparison of the value of learning styles with other factors indicated that such variables have a stronger impact on learner performance than learning styles. Further research is needed to draw a general picture about the effectiveness of such variables. This can be achieved by recruiting heterogeneous and larger sample as well as replicating the study in different courses and universities.

\section{Acknowledgement}

The authors are grateful to the Iraqi Ministry of Higher Education and Scientific Research for sponsoring this study. They also thank Associate Prof. Dr. Safaa Al-Mamory at the University of Babylon for his valuable help during carrying out the experiment and Dr. Patrick Parslow at the University of Reading for his constructive comments that helped to enhance the study. 


\section{References}

Akbulut, Y., \& Cardak, C. S. (2012). Adaptive educational hypermedia accommodating learning styles: A content analysis of publications from 2000 to 2011. Computers \& Education, 58(2), 835-842. http://dx.doi.org/10.1016/j.compedu.2011.10.008

Al-Azawei, A., \& Badii, A. (2014). State of The Art of Learning Styles-Based Adaptive Educational Hypermedia Systems (LS-BAEHSs). International Journal of Computer Science and Information Technology, 6(3), 1-19. http://dx.doi.org/10.5121/ijcsit.2014.6301

Allert, J. (2003). A Companion Technology Approach to CS1 : Handheld Computers with Concept Visualization Software. ITiCSE '03: Proceedings of the 8th Annual Conference on Innovation and Technology in Computer Science Education, 134-138.

Boyle, G. J., Neumann, D. L., Furedy, J. J., \& Westbury, H. R. (2010). Sex differences in verbal and visual-spatial tasks under different hemispheric visual-field presentation conditions. Perceptual and Motor Skills, 110(2), 396-410. http://dx.doi.org/10.2466/PMS.110.2.396-410

Brown, E. (2007). The use of learning styles in adaptive hypermedia, (October). PhD Dessertation. Retrieved from http://etheses.nottingham.ac.uk/577/

Brown, E. J., Brailsford, T. J., Fisher, T., \& Moore, a. (2009). Evaluating Learning Style Personalization in Adaptive Systems: Quantitative Methods and Approaches. IEEE Transactions on Learning Technologies, 2(1), 10-22. http://dx.doi.org/10.1109/TLT.2009.11

Cagiltay, N. E., Yildirim, S., \& Aksu, M. (2006). Students' preferences on web-based instruction: Linear or non-linear. In Educational Technology and Society, 9, 122-136.

Campbell, V., \& Johnstone, M. (2010). The Significance of Learning Style with Respect to Achievement in First Year Programming Students. 2010 21st Australian Software Engineering Conference, 165-170. http://dx.doi.org/10.1109/ASWEC.2010.33

Chamillard, a. T., \& Sward, R. E. (2005). Learning styles across the curriculum. ACM SIGCSE Bulletin, 37(3), 241. http://dx.doi.org/10.1145/1151954.1067512

Coffield, F., Moseley, D., Hall, E., \& Ecclestone, K. (2004). Learning styles and pedagogy in post-16 learning: A systematic and critical review. Retrieved from http://sxills.nl/lerenlerennu/bronnen/Learning styles by Coffield e.a..pdf

Dorça, F. A., Lima, L. V., Fernandes, M. A., \& Lopes, C. R. (2013). Comparing strategies for modeling students learning styles through reinforcement learning in adaptive and intelligent educational systems: An experimental analysis. Expert Systems with Applications, 40(6), 2092-2101. http://dx.doi.org/10.1016/j.eswa.2012.10.014

Dunn, R., \& Dunn, K. (1974). Learning Style as a Criterion for Placement in Alternative Programs. Phi Delta Kappan, 56(4), 275-278. 
Felder, R. (1996). Matters of style. ASEE Prism, 6(4), 18-23.

Felder, R., \& Brent, R. (2005). Understanding student differences. Journal of Engineering Education, 94(1), 57-72.

Felder, R. M., \& Soloman, B. A. (n.d.). INDEX OF LEARNING STYLES. Retrieved from http://www.engr.ncsu.edu/learningstyles/ilsweb.html

Felder, R., \& Silverman, L. (1988). Learning and teaching styles in engineering education. Engineering Education, 78(June), 674-681.

Felder, R., \& Spurlin, J. (2005). Applications, reliability and validity of the index of learning styles. International Journal of Engineering Education, 21(1).

Garrison, D. R., \& Kanuka, H. (2004). Blended learning: Uncovering its transformative potential in higher education. Internet and Higher Education, 7(2), 95-105. http://dx.doi.org/10.1016/j.iheduc.2004.02.001

Graf, S., Viola, S. R., \& Leo, T. (2007). In-Depth Analysis of the Felder-Silverman Learning Style Dimensions. Journal of Research on Technology in Education, 40(1), 79-93. http://dx.doi.org/10.1080/15391523.2007.10782498

Hawk, T., \& Shah, A. (2007). Using learning style instruments to enhance student learning. Decision Sciences Journal of Innovative Education, 5(1), 1-19. Retrieved from http://onlinelibrary.wiley.com/doi/10.1111/j.1540-4609.2007.00125.x/full

Kolb, D. A. (1981). Learning styles and disciplinary difference. Retrieved from http://www.ltsn-01.ac.uk/static/uploads/workshop_resources/178/178_Learning_styles_ and_disciplinary_difference.pdf

Lau, W. W. F., \& Yuen, A. H. K. (2009). Exploring the effects of gender and learning styles on computer programming performance: implications for programming pedagogy. British Journal of Educational Technology, 40(4), 696-712. http://dx.doi.org/10.1111/j.1467-8535.2008.00847.x

Litzinger, T. a., Lee, S. H., Wise, J. C., \& Felder, R. M. (2007). A Psychometric Study of the Index of Learning Styles( ${ }^{\circ}$. Journal of Engineering Education, 96(4), 309-319. http://dx.doi.org/10.1002/j.2168-9830.2007.tb00941.x

López-Pérez, M. V., Pérez-López, M. C., \& Rodríguez-Ariza, L. (2011). Blended learning in higher education: Students' perceptions and their relation to outcomes. Computers \& Education, 56(3), 818-826. http://dx.doi.org/10.1016/j.compedu.2010.10.023

Lu, J., Yu, C.-S., \& Liu, C. (2003). Learning style, learning patterns, and learning performance in a WebCT-based MIS course. Information \& Management, 40(6), 497-507. http://dx.doi.org/10.1016/S0378-7206(02)00064-2

Mayer, R. E. (2011). Does styles research have useful implications for educational practice? Learning and Individual Differences, 21(3), 319-320. http://dx.doi.org/10.1016/j.lindif.2010.11.016 
Nussbaum, M., Alvarez, C., McFarlane, A., Gomez, F., Claro, S., \& Radovic, D. (2009). Technology as small group face-to-face Collaborative Scaffolding. Computers \& Education, 52(1), 147-153. http://dx.doi.org/10.1016/j.compedu.2008.07.005

Pallant, J. (2013). SPSS Survival Manual: A step by step guide to data analysis using IBM SPSS (5th ed.). McGrawHill.

Pashler, H., \& McDaniel, M. (2008). Learning styles concepts and evidence. Psychological science in the public interest, 9(3), 105-119.

Pioro, B. T. (2004). Performance in an Introductory Computer Programming Course as a Predictor of Future Success for Engineering and Computer Science Majors Authors: International Conference on Engineering Education, Gainesville, Fl, USA.

Procter, C. (2003). Blended Learning in Practice, (September). Retrieved from http://usir.salford.ac.uk/27428/2/BlendedLearningInPractice.pdf

Riener, C., \& Willingham, D. (2010). The myth of learning styles. The Magazine of Higher Learning, (October), 32-36.

Solimeno, A., Mebane, M. E., Tomai, M., \& Francescato, D. (2008). The influence of students and teachers characteristics on the efficacy of face-to-face and computer supported collaborative learning. Computers \& Education, 51(1), 109-128. http://dx.doi.org/10.1016/j.compedu.2007.04.003

Vanderheyden, K., \& De Baets, S. (2015). Does cognitive style diversity affect performance in dyadic student teams? Learning and Individual Differences, 38, 143-150. http://dx.doi.org/10.1016/j.lindif.2015.01.006

Zapalska, A., \& Brozik, D. (2006). learning styles and online education. Campus-Wide Information Systems, 23(5), 325-335. http://dx.doi.org/10.1108/10650740610714080

Zhang, L. F. (2013). The malleability of intellectual styles. Cambridge University Press.

Zywno, M. (2003). A contribution to validation of score meaning for Felder-Soloman's index of learning styles. In Proceedings of the 2003 American Society for Engineering Education Annual Conference \& Exposition, 119, 1-5.

\section{Copyright Disclaimer}

Copyright for this article is retained by the author(s), with first publication rights granted to the journal.

This is an open-access article distributed under the terms and conditions of the Creative Commons Attribution license (http://creativecommons.org/licenses/by/3.0/). 